\title{
Using simulations of the last millennium to understand climate variability seen in palaeo-observations: similar variation of Iceland-Scotland overflow strength and Atlantic Multidecadal Oscillation
}

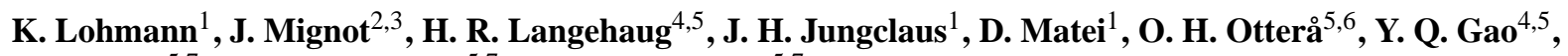 \\ T. L. Mjell ${ }^{5,7}$, U. S. Ninnemann ${ }^{5,7}$, and H. F. Kleiven ${ }^{5,7}$ \\ ${ }^{1}$ Max Planck Institute for Meteorology, Hamburg, Germany \\ ${ }^{2}$ Sorbonne Universités (UPMC, Univ Paris 06)-CNRS-IRD-MNHN, LOCEAN Laboratory, \\ 4 place Jussieu, 75005 Paris, France \\ ${ }^{3}$ Climate and Environmental Physics and Oeschger Centre of Climate Change Research, University of Bern, Bern, \\ Bern, Switzerland \\ ${ }^{4}$ Nansen Environmental and Remote Sensing Center, Bergen, Norway \\ ${ }^{5}$ Bjerknes Centre for Climate Research, Bergen, Norway \\ ${ }^{6}$ Uni Research, Bergen, Norway \\ ${ }^{7}$ Department of Earth Science, University of Bergen, Bergen Norway
}

Correspondence to: K. Lohmann (katja.lohmann@mpimet.mpg.de)

Received: 12 April 2014 - Published in Clim. Past Discuss.: 11 August 2014

Revised: 13 December 2014 - Accepted: 16 December 2014 - Published: 10 February 2015

\begin{abstract}
A recent palaeo-reconstruction of the strength of the Iceland-Scotland overflow during the last 600 years suggests that its low-frequency variability exhibits strong similarity with palaeo-reconstructions of the Atlantic Multidecadal Oscillation (AMO). The underlying mechanism of the similar variation remains unclear, however, based on palaeo-reconstructions alone. In this study we use simulations of the last millennium driven by external forcing reconstructions with three coupled climate models in order to investigate possible mechanisms underlying the similar variation of Iceland-Scotland overflow strength and AMO index. Similar variation of the two time series is also largely found in the model simulations. Our analysis indicates that the basin-wide AMO index in the externally forced simulations is dominated by the low-latitude sea surface temperature (SST) variability and is not predominantly driven by variations in the strength of the Atlantic meridional overturning circulation (MOC). This result suggests that a large-scale link through the strength of the MOC is not sufficient to explain the (simulated) similar variation of Iceland-Scotland overflow strength and AMO index. Rather, a more local link
\end{abstract}

through the influence of the Nordic seas surface state and density structure, which are positively correlated with the AMO index, on the pressure gradient across the IcelandScotland ridge is responsible for the (simulated) similar variation. In the model simulation showing a weaker correlation between the Iceland-Scotland overflow strength and the AMO index, the wind stress in the Nordic seas also influences the overflow strength. Our study demonstrates that palaeo-climate simulations provide a useful tool to understand mechanisms and large-scale connections associated with the relatively sparse palaeo-observations.

\section{Introduction}

Marine sediment cores provide palaeo-climatic information by allowing the reconstruction of marine quantities back in time. Apart from temperature and salinity, which are deduced from the chemical properties of plankton shells, the strength of the near-bottom flow can also be reconstructed based on the mean sediment grain size (with larger grain size 

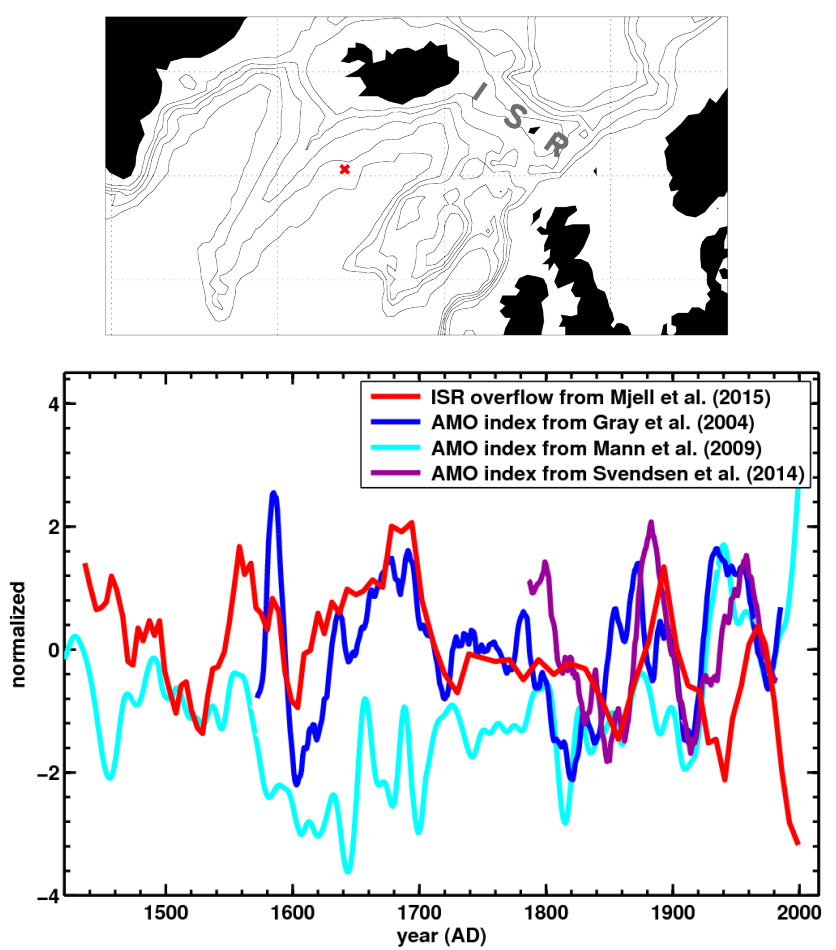

Figure 1. Reconstructed AMO index from Gray et al. (2004, blue), Mann et al. (2009, cyan) and Svendsen et al. (2014, purple); Iceland-Scotland overflow strength from Mjell et al. (2015, red). The AMO indices are shown as annual values with an 11year running mean filter applied. For the Iceland-Scotland overflow strength, the original time series has irregular dates and is smoothed by applying a three-point running mean filter. All time series are normalised by the respective standard deviations. The map shows the location of the sediment core on which the reconstructed Iceland-Scotland overflow strength is based (topography is shown for depths of 500, 1000, 1500, 2000 and $2500 \mathrm{~m}$ ). Figure adapted from Mjell et al. (2015).

corresponding to stronger near-bottom flow) if the sediment cores are taken along sediment drifts, where there is lateral transport and input of sediments. Due to this lateral sediment transport by deep-ocean currents, the pattern of oceanic sediment drifts mirrors the path of the deep-ocean currents (Wold, 1994). Recently, a reconstruction of the IcelandScotland overflow strength for the last 600 years has become available (Mjell et al., 2015) based on a sediment core located downstream of the Iceland-Scotland ridge (ISR) within the Gardar sediment drift at the eastern flank of the Reykjanes Ridge. The reconstructed overflow time series exhibits pronounced variability on multidecadal to centennial time scales, which agrees well with the variability suggested from a previous study by Boessenkool et al. (2007) based on the mean sediment grain size from a sediment core spanning the last 250 years, located downstream of the core discussed in Mjell et al. (2015).

Mjell et al. (2015) further reveal a strong similarity between the low-frequency variability of the Iceland-Scotland overflow strength and reconstructions (e.g. Gray et al., 2004) of the Atlantic Multidecadal Oscillation (AMO), with periods of strong flow associated with Atlantic-wide warmth (Fig. 1). The AMO is the leading mode of sea surface temperature (SST) variability in the North Atlantic on multidecadal time scales (e.g. Schlesinger and Ramankutty, 1994, based on temperature records; Delworth and Mann, 2000, based on temperature records and coupled climate models). Palaeoreconstructions are, however, still very rare and do not allow a detailed investigation of mechanisms underlying the (co)variability suggested from them.

A broader insight into the palaeo-climate can be provided by coupled climate model simulations driven by external forcing reconstructions, in particular variations in the solar irradiance or major volcanic eruptions. AMO, North Atlantic SST variability in general and some aspects of the oceanic circulation, such as the North Atlantic gyre and especially the Atlantic meridional overturning circulation (MOC), in externally forced simulations have recently been discussed in the literature (e.g. Goosse and Renssen, 2006; Stenchikov et al., 2009; Otterå et al., 2010; Mignot et al., 2011; Swingedouw et al., 2011; Zhong et al., 2011; Ortega et al., 2012; Park and Latif, 2012; Zanchettin et al., 2012; Lehner et al., 2013; Swingedouw et al., 2013). They arrive, however, at partly contradictory conclusions. Attempts to explain the differences in the oceanic response to an external forcing point towards a dependence on the simulated background state (Zanchettin et al., 2012) as well as on the frequency and amplitude of major volcanic eruptions in the time period considered for the analysis (Mignot et al., 2011). Reconstructions of external forcing components are also subject to some debate, such as the amplitude of solar radiation variability. In contrast to North Atlantic SST and MOC, the overflow from the Nordic seas through the Denmark Strait and across the ISR has not been studied (much) in externally forced simulations.

Here we use simulations of the last millennium driven by external forcing reconstructions with three coupled climate models to investigate mechanisms underlying the similar variation of Iceland-Scotland overflow strength and AMO index suggested from palaeo-reconstructions (Mjell et al., 2015). Two possible mechanisms linking the two time series are discussed. The first is (i) a large-scale link through the strength of the MOC in the sense that a warm (cold) phase of the AMO is associated with a strong (weak) MOC that is influenced by strong (weak) Iceland-Scotland overflow. Indeed, there is evidence from previous studies based on ocean reanalysis and control simulations with coupled climate models of an influence of the Denmark Strait overflow variability on the variability of the MOC (e.g. Jungclaus et al., 2005; Köhl and Stammer, 2008) as well as of the association of multidecadal SST anomalies in the North Atlantic, as reflected in the AMO index, with multidecadal MOC variations (e.g. Delworth and Mann, 2000; Latif et al., 2004; Knight et al., 2005). Mechanism (ii) consists of a more local link through the influence of the Nordic seas surface 
state and density structure, which are positively correlated with the basin-wide AMO index as discussed below, on the pressure gradient across the ISR. Previous observational (e.g. Hansen et al., 2001) and modelling (e.g. Jungclaus et al., 2008) studies suggest that the overflow transport through the Faroe-Shetland channel (FSC), which carries the majority of the overflow between Iceland and Scotland, is controlled by internal hydraulics and affected by the baroclinic pressure gradient across the ISR in the core depth of the overflow. Further observational (e.g. Hansen and Østerhus, 2007) and modelling (e.g. Olsen et al., 2008; Sandø et al., 2012) studies add the importance of the barotropic pressure gradient. Note that mechanism (ii) may also involve the large-scale ocean circulation through the transport of heat and salt from the subtropics into the Nordic seas.

Our study is organised as follows: the models and the experimental set-up as well as the simulated Iceland-Scotland overflow strength and AMO index are described in Sect. 2. In Sect. 3, the two possible mechanisms underlying the similar variation of Iceland-Scotland overflow strength and AMO index introduced above are investigated. The results are discussed in Sect. 4 and the main conclusions are given in Sect. 5.

\section{Model description and simulated variability of Iceland-Scotland overflow strength and AMO index}

\subsection{Model description and experimental set-up}

Our study is based on simulations of the last millennium driven by external forcing reconstructions conducted with three global coupled climate models, namely the Max Planck Institute for Meteorology Earth System Model (MPI-ESM), the coupled climate model developed at the Institute PierreSimon Laplace (IPSLCM4_v2, hereafter IPSLCM4) and the Bergen climate model (BCM). These model simulations were made available within the EU project THOR (ThermoHaline Overturning - at Risk?). We limit our study to model simulations from the project partners as non-standard simulated quantities, such as the overflow transport across the ISR, are needed.

In MPI-ESM, the atmosphere general circulation model (GCM) ECHAM6 (Stevens et al., 2013) is coupled to the ocean/sea ice GCM MPIOM (Marsland et al., 2003; Jungclaus et al., 2013; Notz et al., 2013) using the OASIS3 coupler (Valcke et al., 2003). The atmosphere GCM is run at a horizontal resolution of T63 (spectral grid with truncation at wave number 63 , corresponding to about $1.875^{\circ}$ on a Gaussian grid) and 47 vertical levels, resolving the stratosphere up to $0.01 \mathrm{hPa}$. The ocean GCM applies a conformal mapping grid in the horizontal with the North Pole shifted to southern Greenland (to circumvent grid singularities in the computational ocean domain), featuring a nominal resolution of $1.5^{\circ}$. The convergence of the mesh size towards the poles translates into a grid spacing of 15 to $100 \mathrm{~km}$ in the North Atlantic.
Vertically, 40 unevenly spaced z-levels are used with the first 20 levels covering the upper $700 \mathrm{~m}$ of the water column.

In IPSLCM4 (Marti et al., 2010), the atmosphere GCM LMDz4 (Hourdin et al., 2006) is coupled to the ocean GCM OPA8.2 (Madec et al., 1998) and the sea ice model LIM2 (Fichefet and Maqueda, 1997) using the OASIS2.4 coupler (Valcke et al., 2000). The atmosphere GCM is run at a horizontal resolution of $3.75^{\circ}$ (in longitude) $\times 2.5^{\circ}$ (in latitude) and 19 vertical levels, resolving the stratosphere up to $3 \mathrm{hPa}$. The ocean GCM uses the ORCA2 grid in the horizontal, i.e. a conformal mapping, tripolar grid with two poles placed in the Northern Hemisphere over land (American and Asian continents) to avoid grid singularities in the computational ocean domain. The averaged horizontal resolution is $2^{\circ}$ with the meridional grid spacing refined to $0.5^{\circ}$ around the Equator (to better resolve the dynamics near the Equator). The convergence of the mesh size towards the poles translates into a grid spacing of about 100 to $200 \mathrm{~km}$ in the North Atlantic. Vertically, 31 unevenly spaced z-levels are used with the first 20 levels covering the upper $600 \mathrm{~m}$ of the water column.

In BCM (Furevik et al., 2003; Otterå et al., 2009), the atmosphere GCM ARPEGE (Deque et al., 1994) is coupled to the ocean GCM MICOM (Bleck and Smith, 1990; Bleck et al., 1992) and the sea ice model GELATO (SalasMelia, 2002) using the OASIS (version 2) coupler (Terray and Thual, 1995). In the MICOM model used in BCM, several important aspects deviate from the original model (e.g. Otterå et al., 2009), most importantly the conservation of heat and salt. The atmosphere GCM is run at a horizontal resolution of T63 (spectral grid with truncation at wave number 63; corresponding to about $1.875^{\circ}$ on a Gaussian grid) and 31 vertical levels, resolving the stratosphere up to $10 \mathrm{hPa}$. The ocean GCM applies a conformal mapping grid in the horizontal with the North Pole located over Siberia to avoid grid singularities in the computational ocean domain, featuring a nominal resolution of $2.4^{\circ}$ with the meridional grid spacing near the Equator being gradually decreased up to $0.8^{\circ}$ at the Equator (to better resolve the dynamics near the Equator). The grid spacing in the North Atlantic amounts to about 150 to $200 \mathrm{~km}$. Vertically, 34 isopycnal layers with potential densities ranging from $\sigma_{2}=30.119$ to $37.800 \mathrm{~kg} \mathrm{~m}^{3}$ are used with a non-isopycnic surface mixed layer on top.

With respect to the simulated decadal-to-centennial-scale climate variability in the North Atlantic, recent multi-model control simulation studies (including the three models used here) discuss differences among the coupled climate models in both the representation of the low-frequency North Atlantic climate variability as well as in the mechanisms and feedbacks involved (e.g. Menary et al., 2012; Langehaug et al., 2012b; Gastineau and Frankignoul, 2012; Ba et al., 2014).

Regarding the external forcing reconstructions used to force the model simulations, volcanic aerosols are based on reconstructions by Crowley et al. (2008) in the MPI-ESM simulation, Ammann et al. (2003) and Gao et al. (2008) in 
the IPSLCM4 simulation and Crowley et al. (2003) in the BCM simulation. The differences between these reconstructions are, however, rather minor. The volcanic aerosols are distributed over a couple of stratospheric levels and the effect on the radiative forcing is calculated online in all models. For the solar forcing, a small amplitude of variations based on total solar irradiance (TSI) reconstructions by Vieira and Solanki (2010) and Vieira et al. (2011) is used in the MPIESM and IPSLCM4 simulation, with an increase in TSI of $0.1 \%$ from the 17 th century Maunder Minimum to present time. A weak scaling of solar forcing is indeed recommended in the protocol of the third phase of the Paleoclimate Modelling Intercomparison Project (PMIP3; Schmidt et al., 2011). In the BCM simulation, a TSI reconstruction based on Crowley et al. (2003) is used that exhibits a larger amplitude than the one used in the two other models. Changes in orbital parameters are taken into account in the MPI-ESM and IPSLCM4 simulation but are not included in the BCM simulation.

With respect to anthropogenic forcing, the most important well-mixed greenhouse gases are taken into account in the MPI-ESM and IPSLCM4 simulation. In the MPI-ESM simulation, land cover changes (Pongratz et al., 2008) and anthropogenic aerosols are also considered. In the IPSLCM4 simulation, the vegetation is set to modern climatology from Myneni et al. (1997). Anthropogenic aerosol forcing is not included in the IPSLCM4 simulation, leading to a stronger warming trend in the recent decades compared to the MPIESM simulation and reconstructions. In the BCM simulation, no anthropogenic forcing components are included. Given these differences, the discussion of possible mechanisms underlying a similar variation of Iceland-Scotland overflow strength and AMO index is limited to the pre-industrial period in the MPI-ESM and IPSLCM4 simulation, mainly excluding the effect of the anthropogenic forcing components.

For MPI-ESM, a 400-year adaptation run, starting from the pre-industrial control simulation as described in Jungclaus et al. (2013), is performed under orbital forcing conditions representing the year AD 850. Afterwards, the externally forced simulation is performed for the period AD 850 to 2005. For a more detailed description of the simulation, we refer the reader to Jungclaus et al. (2015). For IPSLCM4, after a spin-up phase of 310 years the externally forced simulation is performed for the period AD 850 to 2000. For a more detailed description of the simulation we refer the reader to Mignot et al. (2011) and references therein. Note that this simulation was part of PMIP2 and differs from the one included in the more recent PMIP3. For BCM, after a spin-up phase of 500 years (Otterå et al., 2009) the externally forced simulation is performed for the period AD 1400 to 2000. For a more detailed description of the simulation we refer the reader to Otterå et al. (2010) and references therein.

In this study we focus on the low-frequency variability of the Iceland-Scotland overflow strength and the AMO index.
Therefore, all model data are annual values with a 21 -year running mean filter applied.

\subsection{Iceland-Scotland overflow strength and AMO index in the simulations}

Here we define the Iceland-Scotland overflow strength and the AMO index and investigate their variability in the three last-millennium simulations presented above. The reconstruction from Mjell et al. (2015) represents the strength of the near-bottom current at the eastern flank of the Reykjanes Ridge along the flow path of the Iceland-Scotland overflow water. In the models, we have access to the full velocity field and thus estimate the strength of the IcelandScotland overflow directly. The latter is defined as the total transport out of the Nordic seas across the ISR with a density threshold of $\sigma>27.8 \mathrm{~kg} \mathrm{~m}^{-3}$ in MPI-ESM and IPSLCM4 and as the net transport across the ISR with a density threshold of $\sigma_{2}>36.946 \mathrm{~kg} \mathrm{~m}^{-3}$ (corresponding to about $\sigma>27.83 \mathrm{~kg} \mathrm{~m}^{-3}$ ) in BCM. We note that the difference in defining the overflow across the ISR as transport out of the Nordic seas or as net transport is negligible because a transport into the Nordic seas with the given density threshold generally does not exist.

Mean overflow transports amount to $3.0 \mathrm{~Sv}$ (1 Sverdrup $=10^{6} \mathrm{~m}^{3} \mathrm{~s}^{-1}$ ) in MPI-ESM, $2.7 \mathrm{~Sv}$ in IPSLCM4 and 3.6 Sv in BCM, which is in reasonable agreement with observational estimates of about 3.5 Sv (e.g. Hansen et al., 2008). In contrast to observations (e.g. Hansen et al., 2008) where an overflow transport of about $1 \mathrm{~Sv}$ is found between Iceland and the Faroe Islands, the overflow transport across the ISR is restricted to the FSC in MPI-ESM and BCM. In IPSLCM4, an overflow transport of $0.5 \mathrm{~Sv}$ is found between Iceland and the Faroe Plateau. One major bias in the three model simulations used here concerns the flow path of the IcelandScotland overflow water south of the ISR, which is not realistically simulated in the (relatively coarse-resolution) model configurations (e.g. Langehaug et al., 2012a). In contrast to observations, most of the Iceland-Scotland overflow water spreads southward in the eastern North Atlantic basin rather than flowing around the Reykjanes Ridge (through fracture zones in the Mid-Atlantic Ridge) and joining the Denmark Strait overflow water and the deep western boundary current. Due to this model bias, the influence of the Iceland-Scotland overflow strength on the MOC variability might be underestimated in the models.

We define the AMO index as the area average of basinwide North Atlantic SST encompassing the region $75^{\circ}$ to $7.5^{\circ} \mathrm{W}$ and $0^{\circ}$ to $60^{\circ} \mathrm{N}$, following Otterå et al. (2010). This definition does not include the Nordic seas, which is important for the variability of the Iceland-Scotland overflow strength as discussed below. However, AMO index and Nordic seas SST in the model simulations are positively correlated, as discussed below, and the conclusions of our study do not change if the AMO index is based on a larger re- 

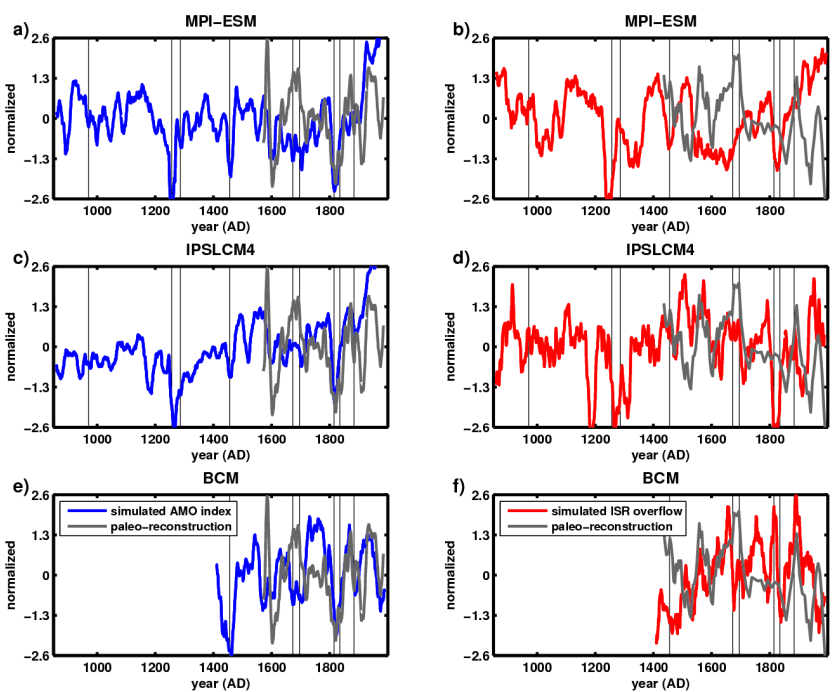

Figure 2. Left panels: anomalous simulated AMO index (blue line) in MPI-ESM (a), IPSLCM4 (c) and BCM (e) compared to the AMO reconstruction (grey line) from Gray et al. (2004). Right panels: anomalous simulated overflow transport across the ISR (red line) in MPI-ESM (b), IPSLCM4 (d) and BCM (f) compared to the reconstructed Iceland-Scotland overflow strength (grey line) from Mjell et al. (2015). All time series are normalised by the respective standard deviations. Simulated time series are annual values with a 21year running mean filter applied. The vertical lines indicate years with major volcanic eruptions (following Zanchettin et al., 2012).

gion encompassing the Nordic seas. We note also that in this definition of the AMO index, the influence of (natural and anthropogenic) external forcing is not removed, as opposed to definitions by e.g. Knight et al. (2005) or Trenberth and Shea (2006).

We compare the simulated Iceland-Scotland overflow strength and AMO index with the reconstruction from Mjell et al. (2015) and Gray et al. (2004) respectively (Fig. 2). Other AMO reconstructions (Mann et al., 2009; Svendsen et al., 2014) basically show similar low-frequency variability as the AMO reconstruction from Gray et al. (2004), especially after about year AD 1750 (Fig. 1). In contrast to the AMO reconstruction from Gray et al. (2004), the AMO reconstruction from Mann et al. (2009) does not show the warm phase during the second half of the 17th century. The simulated and reconstructed AMO indices (left panels in Fig. 2) agree reasonably in the phasing of cold and warm periods. The best agreement is found for the cold event following the major volcanic eruption in year $\mathrm{AD} 1815$, indicating that the AMO index is influenced by the external forcing as stated in, e.g., Otterå et al. (2010) and Zanchettin et al. (2013). Concerning the Iceland-Scotland overflow strength (right panels in Fig. 2), the simulated and reconstructed time series partly agree in the phasing of periods with strong and weak overflow in BCM and especially in IPSLCM4, suggesting that the
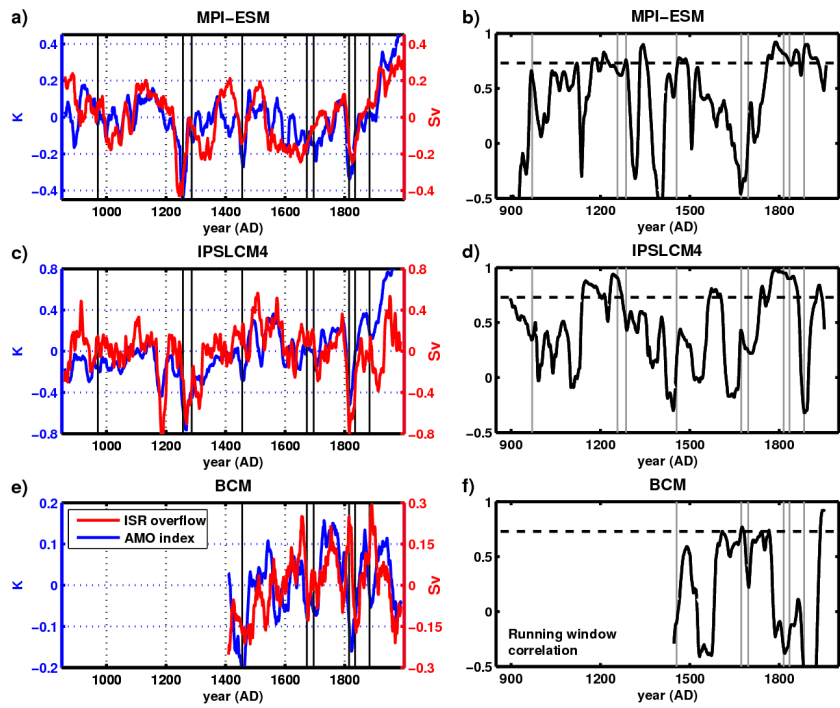

Figure 3. Left panels: simulated anomalous AMO index (blue line; in K) and overflow transport across the ISR (red line; in Sv) in MPIESM (a), IPSLCM4 (c) and BCM (e). All time series are annual values with a 21-year running mean filter applied. Right panels: running correlation (junk length of 75 years) between the AMO index and the overflow transport across the ISR from the left panels in MPI-ESM (b), IPSLCM4 (d) and BCM (f). In all panels, the vertical lines indicate years with major volcanic eruptions (following Zanchettin et al., 2012). Correlation coefficients above the dashed line in (b), (d) and (f) are statistically significant at the $95 \%$ confidence level (significance level: 0.73).

external forcing has some influence on the Iceland-Scotland overflow strength.

Based on the palaeo-reconstructions we assess the relation between the low-frequency variability of the IcelandScotland overflow strength and the AMO index in the three models. Similar variation of the two time series is also largely found in the model simulations (left panels in Fig. 3), with zero-lag correlation coefficients for the pre-industrial period (years AD 850 to 1849 ) of 0.67 in MPI-ESM and 0.74 in IPSLCM4. In BCM, the zero-lag correlation coefficient $(0.39)$ is just above the significance level. It is interesting to note that in MPI-ESM and IPSLCM4, cold periods in the AMO index coincide with very weak Iceland-Scotland overflow. Most of these cold events coincide with major volcanic eruptions (around years AD 1258, 1456 and 1815 in MPI-ESM and around years AD 1258 and 1815 in IPSLCM4) in agreement with previous studies (Mignot et al., 2011; Zanchettin et al., 2012). However, the cold event at the end of the 12th century in IPSLCM4 is not related to any major volcanic eruption. Cold events in the subpolar North Atlantic have also been attributed to internal variability (e.g. MorenoChamarro et al., 2015; using the same MPI-ESM simulation as used in our study). The running correlation (junk length of 75 years) between the Iceland-Scotland overflow strength and the AMO index (right panels in Fig. 3) is high between 
the two time series during the cold events. However, in all three models, high (low) correlation between the IcelandScotland overflow strength and the AMO index is not always related to periods with (without) major volcanic eruptions.

As indicated above, for the discussion of possible mechanisms underlying the (simulated) similar variation of Iceland-Scotland overflow strength and AMO index, the analysis is limited to the pre-industrial period (years AD 850 to 1849) in MPI-ESM and IPSLCM4 in order to avoid the 20th century warming signal due to the anthropogenic greenhouse gas forcing. In IPSLCM4 a model drift is found during the pre-industrial period (due to the relatively short spin-up phase). All IPSLCM4 data are therefore detrended prior to the analysis following Servonnat et al. (2010) and Mignot et al. (2011). The BCM simulation does not include anthropogenic forcing but shows a model drift during the first two centuries (Fig. 3e). Therefore, the analysis is limited to the period between years AD 1550 and 1999.

\section{Investigation of possible mechanisms underlying the similar variation of Iceland-Scotland overflow strength and AMO index}

In this section we will investigate the two mechanisms proposed in the introduction as possible explanations for the similar variation of Iceland-Scotland overflow strength and AMO index, suggested from palaeo-reconstructions and also largely found in the model simulations. These mechanisms are (i) a large-scale link through the strength of the MOC and (ii) a more local link through the influence of the Nordic seas surface state and density structure on the Iceland-Scotland overflow strength.

\subsection{Mechanism (i): Iceland-Scotland overflow strength and AMO index linked through the strength of the MOC?}

Mechanism (i) suggests a similar variation of IcelandScotland overflow strength and AMO index due to a warm (cold) phase of the AMO being related to a strong (weak) MOC that is influenced by strong (weak) Iceland-Scotland overflow. The maximum strength of the North Atlantic MOC is located at about $30^{\circ} \mathrm{N}$ in MPI-ESM, $35^{\circ} \mathrm{N}$ in BCM and $45^{\circ} \mathrm{N}$ in IPSLCM4 at a depth of about $1000 \mathrm{~m}$. We note that our conclusions do not change if a fixed latitude of $30^{\circ} \mathrm{N}$ is used for all models.

In the framework of the last millennium, the basin-wide North Atlantic SST variability, as reflected in the AMO index, is dominated by the relatively large (sub)tropical North Atlantic region (left panels in Fig. 4), as stated in Otterå et al. (2010). The highest correlation coefficients between the AMO index and the North Atlantic SST are, in all three models, found in the tropical and subtropical region with maximum correlation coefficients of the order of 0.8 to 0.9 . This
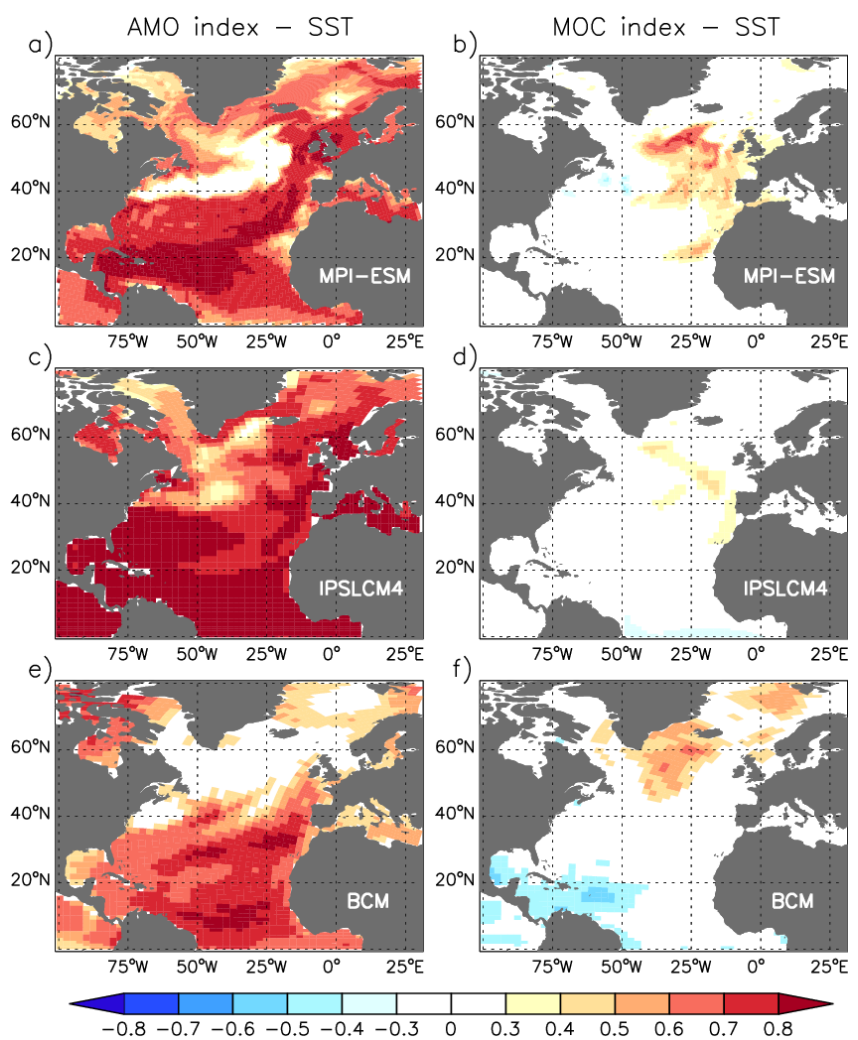

Figure 4. Left panels: zero-lag correlation coefficients between the AMO index and the North Atlantic SST in MPI-ESM (a), IPSLCM4 (c) and BCM (e). Right panels: correlation coefficients between the maximum strength of the North Atlantic MOC and the North Atlantic SST in MPI-ESM (b), IPSLCM4 (d) and BCM (f). The MOC index is leading by 5 years. The correlation analysis is based on annual values for the period AD 850 to 1849 (MPI-ESM, IPSLCM4) and AD 1550 to 1999 (BCM) with a 21-year running mean filter applied. For IPSLCM4, the data have been linearly detrended prior to the analysis to account for the model drift. Only correlation coefficients statistically significant at the $95 \%$ confidence level are shown (significance level: 0.27 in MPI-ESM and IPSLCM4, 0.4 in BCM).

differs from the correlation pattern arising from internal variability (e.g. Ba et al., 2014) and the one found over the 20th century (Kavvada et al., 2013). The SST in the (sub)tropical regions is indeed largely influenced by the relevant external radiative forcing of the last millennium (solar and volcanic forcing) as suggested in previous modelling studies (e.g. Otterå et al., 2010; Mignot et al., 2011; Terray, 2012). For the SST in the Nordic seas, which is important for the IcelandScotland overflow strength as discussed below, correlation coefficients are of comparable magnitude in MPI-ESM and IPSLCM4, reaching maximum values of 0.7. In BCM, correlation coefficients between the AMO index and the Nordic seas SST are weaker than in the two other models. The lowest correlation coefficients between the AMO index and the North Atlantic SST are found in the subpolar region. This finding is robust within the three models and is also seen in 
Zanchettin et al. (2013) using the reconstructed AMO index from Gray et al. (2004) and simulations of the last millennium with a coarser-resolution MPI-ESM configuration.

On the other hand, the largest influence of the lowfrequency MOC variability on the North Atlantic SST (right panels in Fig. 4) is found in the subpolar region in MPIESM and BCM, in agreement with studies based on control simulations (e.g. Latif et al., 2004; Zhang and Wang, 2013). In MPI-ESM, the significant influence of the MOC on the North Atlantic SST is limited to this region, while in $\mathrm{BCM}$ a significant influence is also found on the SST in the Nordic seas. In IPSLCM4 almost no significant influence of the MOC on the North Atlantic SST is found. We note that in MPI-ESM and IPSLCM4 this differs from the behaviour in the respective control simulation, where the correlation between the maximum strength of the North Atlantic MOC and the North Atlantic SST (not shown) also includes significant correlation coefficients in the Nordic seas, the subtropics and (in IPSLCM4) the subpolar region, consistent with, e.g., Zanchettin et al. (2014, MPI-ESM) and Msadek and Frankingnoul (2009, IPSLCM4). These findings indicate that in MPI-ESM, and even more so in IPSLCM4, the MOC signature on the North Atlantic SST is reduced in the externally forced simulations due to the influence of the external radiative forcing on the SST. Consistently (C. Marini, personal communication, 2013), analysing the same IPSLCM4 simulation as used in our study finds a higher correlation between the $\mathrm{AMO}$ and the MOC if a mode representing the response to volcanic forcing is removed from the AMO.

The region where the highest correlation coefficients between the North Atlantic SST and the maximum strength of the North Atlantic MOC are found (right panels in Fig. 4) coincides with the region where the correlation coefficients between the AMO index and the North Atlantic SST are lowest (left panels in Fig. 4). This suggests that in the externally forced simulations the basin-wide AMO index, which is dominated by the low-latitude SST variability, is not predominantly driven by MOC changes.

In order to investigate more specific periods with strong external forcing, composite analysis with respect to the two cold events in the AMO index following the major volcanic eruptions in years AD 1258 and 1815 (blue lines in Fig. 3) is performed (Fig. 5). The North Atlantic SST anomaly pattern during these cold events shows some similarity compared to the North Atlantic SST pattern associated with the AMO index in general (left panels in Fig. 4; note that here correlation coefficients are shown). Also, the cold SST anomalies found in the subpolar North Atlantic and the Nordic seas during the cold events in MPI-ESM and IPSLCM4 are not predominantly driven by MOC changes because the maximum strength of the MOC does not weaken during the cold events (not shown), which is in agreement with previous studies (e.g. Mignot et al., 2011; Zanchettin et al., 2012).

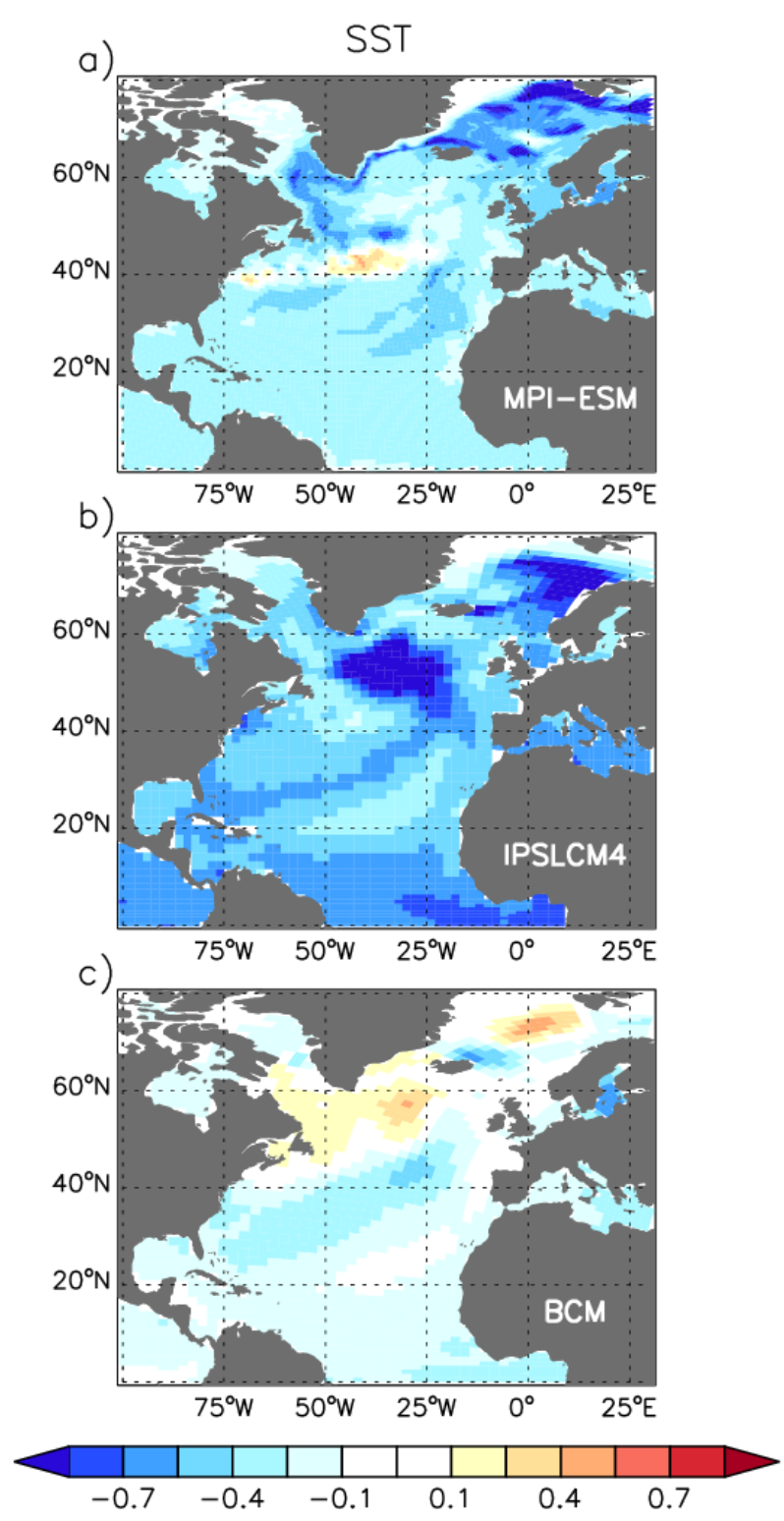

Figure 5. Composite for North Atlantic SST (in K) with respect to the cold events in the AMO index (blue lines in Fig. 3) following the major volcanic eruptions in years AD 1258 and 1815 (BCM only AD 1815) taking into account 15 years centred around the coldest year in MPI-ESM (a), IPSLCM4 (b) and BCM (c). The composites are based on annual anomalies (with respect to the period AD 850 to 1849 in MPI-ESM and IPSLCM4 and AD 1550 to 1999 in BCM) with a 21-year running mean filter applied. For IPSLCM4, the data have been linearly detrended prior to the analysis to account for the model drift.

Based on the results discussed in this section, we conclude that mechanism (i), a link through the strength of the MOC, is not sufficient to explain the (simulated) similar variation of Iceland-Scotland overflow strength and AMO index. 


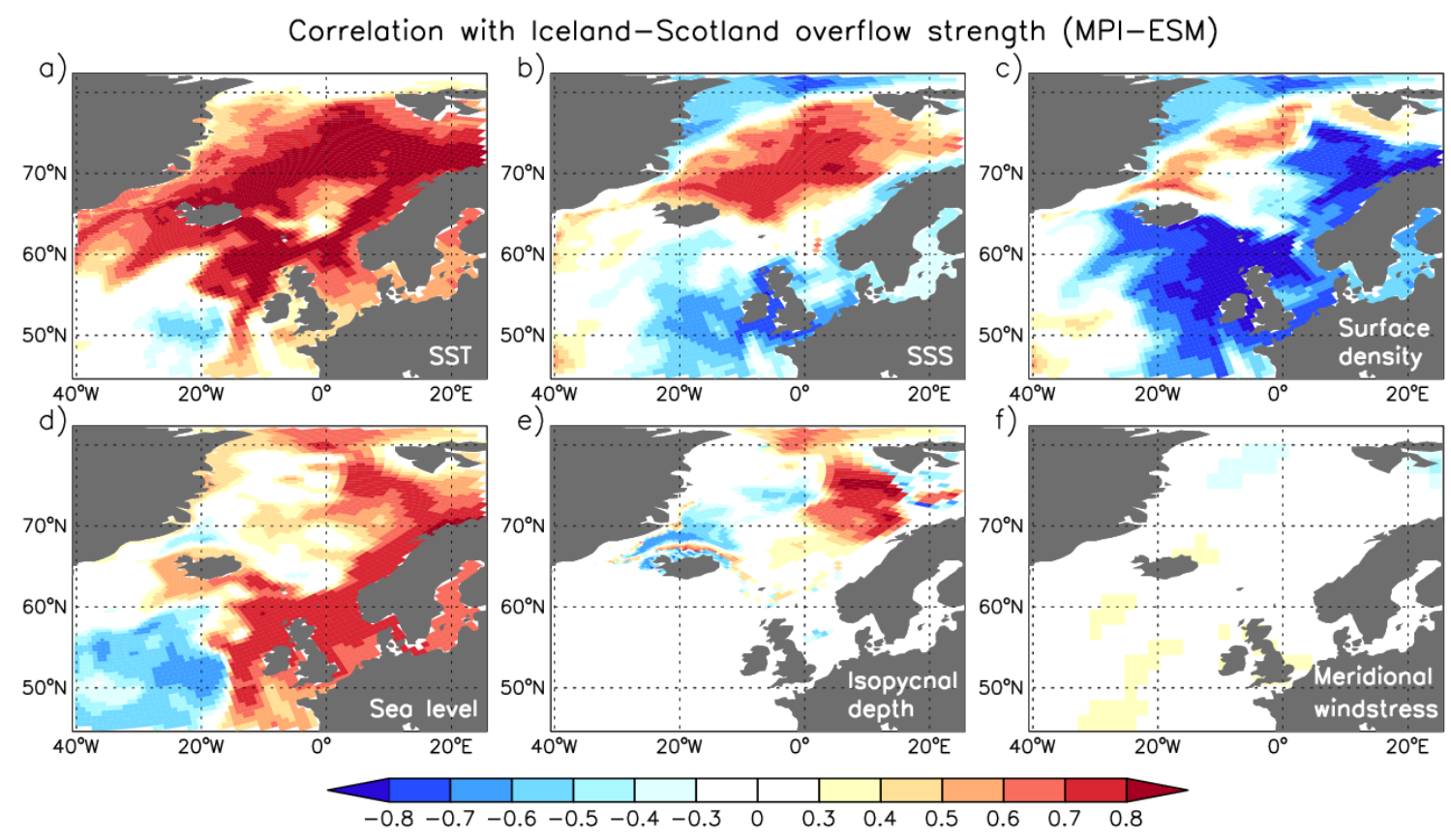

Figure 6. Zero-lag correlation coefficients between the Iceland-Scotland overflow strength and (a) the SST, (b) the SSS, (c) the surface density, (d) the sea surface height (linearly detrended prior to the analysis to account for the non-closed water budget between the atmosphere and the ocean), (e) the depth of the isopycnal $\sigma=27.8 \mathrm{~kg} \mathrm{~m}^{-3}$ and (f) the meridional wind stress component in MPI-ESM. The correlation analysis is based on annual values for the period AD 850 to 1849 with a 21-year running mean filter applied. Only correlation coefficients statistically significant at the $95 \%$ confidence level are shown (significance level: 0.27 ).

\subsection{Mechanism (ii): Iceland-Scotland overflow strength and AMO index linked through the influence of the Nordic seas surface state on the Iceland-Scotland overflow strength?}

According to the literature (e.g. Hansen and Østerhus, 2007; Jungclaus et al., 2008; Olsen et al., 2008; Sandø et al., 2012), the Iceland-Scotland overflow strength is affected by the pressure gradient across the ISR in the core depth of the overflow. Mechanism (ii) thus implies a similar variation of Iceland-Scotland overflow strength and AMO index due to the influence of the Nordic seas surface state and density structure on the pressure gradient across the ISR.

The correlation between the Iceland-Scotland overflow strength and various oceanic quantities in the northeastern North Atlantic in the three models is shown in Figs. 6 to 8 . We discuss only the case of strong Iceland-Scotland overflow, but the correlation pattern can be interpreted in an analogous way for the case of weak overflow. We also use zero-lag correlation coefficients. The correlation pattern representing a lead/lag of a couple of years is rather similar to the zero-lag correlation pattern, probably due to the fact that a 21-year running mean filter is applied to the data prior to the analysis.

Strong Iceland-Scotland overflow is associated with an anomalously warm and salty surface state in the Nordic seas. Maximum correlation coefficients for SST and sea surface salinity (SSS) reach about 0.85 in MPI-ESM (Fig. 6a and b), 0.7 in IPSLCM4 (Fig. 7a and b) and 0.5 in BCM (Fig. 8a and b). For SST, positive correlation coefficients are also found south of the ISR along the path of the North Atlantic current. For SSS, negative correlation coefficients are found in the northwestern part of the Nordic seas in MPI-ESM and IPSLCM4 and in the region close to the Norwegian coast in MPI-ESM. The SSS anomalies in the northwestern part of the Nordic seas are related to less sea ice extent under warmer conditions (not shown), while the reason for the anomalies close to the Norwegian coast remains unclear.

The correlation between the Iceland-Scotland overflow strength and the surface heat/fresh-water flux as well as between the Iceland-Scotland overflow strength and the heat/salt transport across the ISR (not shown) suggests that the anomalously warm Nordic seas surface state associated with strong Iceland-Scotland overflow is to a large extent caused by an increase in the oceanic heat transport across the ISR. Local air-sea heat exchanges mainly have a dampening effect on the Nordic seas SST anomalies. In contrast, a net surface fresh-water loss contributes to the anomalously salty Nordic seas surface state associated with strong Iceland-Scotland overflow, with the exception of the western part of the Nordic seas in BCM. Regarding the salt transport across the ISR, correlation coefficients with the IcelandScotland overflow strength are smaller than for the heat trans- 


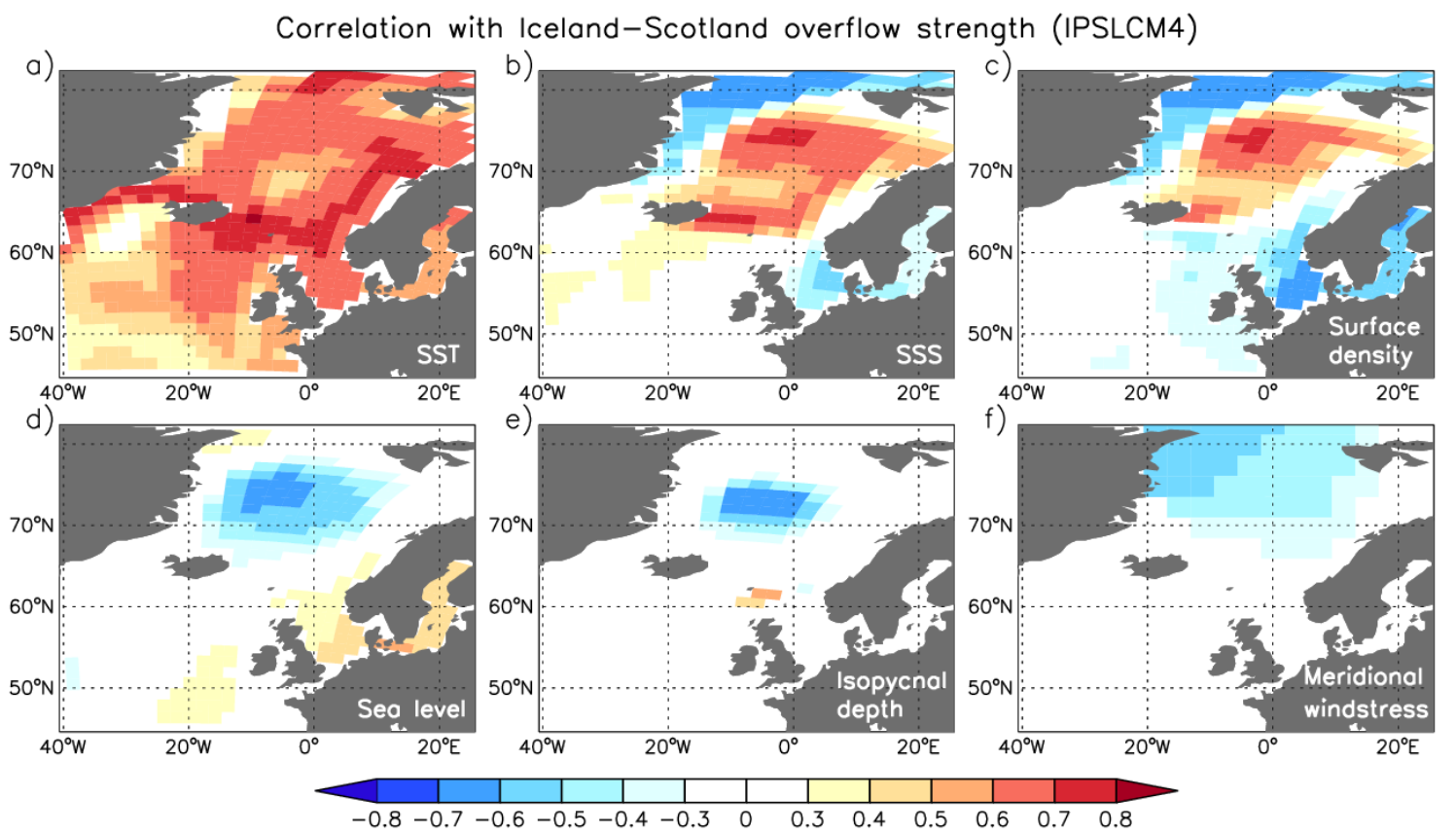

Figure 7. Zero-lag correlation coefficients between the Iceland-Scotland overflow strength and (a) the SST, (b) the SSS, (c) the surface density, (d) the sea surface height, (e) the depth of the isopycnal $\sigma=27.8 \mathrm{~kg} \mathrm{~m}^{-3}$ and (f) the meridional wind stress component in IPSLCM4. The correlation analysis is based on annual values for the period AD 850 to 1849 with a 21-year running mean filter applied. The data have been linearly detrended prior to the analysis to account for the model drift. Only correlation coefficients statistically significant at the $95 \%$ confidence level are shown (significance level: 0.27).

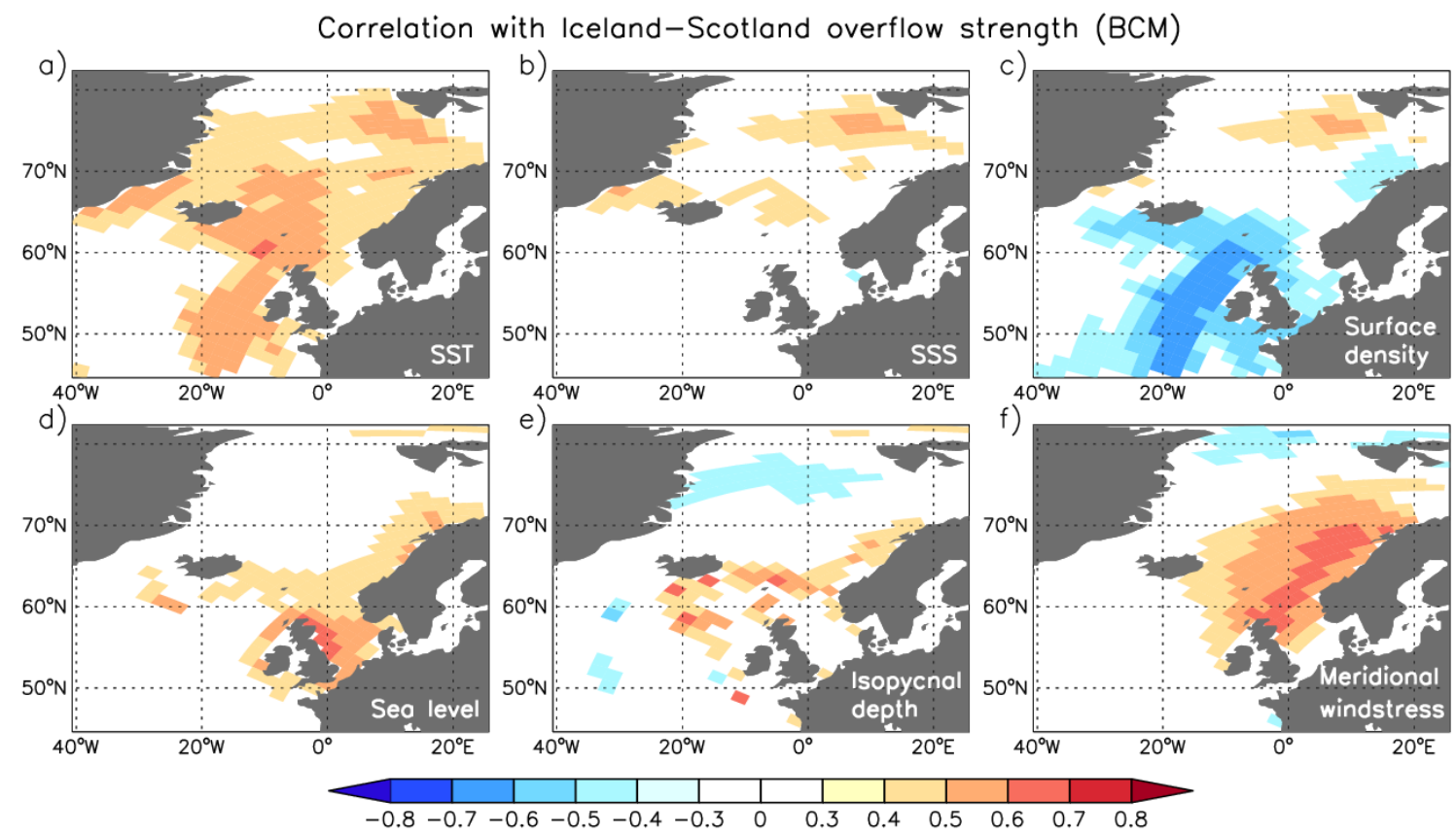

Figure 8. Zero-lag correlation coefficients between the Iceland-Scotland overflow strength and (a) the SST, (b) the SSS, (c) the surface density, (d) the sea surface height (linearly detrended prior to the analysis), (e) the depth of the isopycnal $\sigma_{2}=36.946 \mathrm{~kg} \mathrm{~m}^{-3}$ and (f) the meridional wind stress component in BCM. The correlation analysis is based on annual values for the period AD 1550 to 1999 with a 21 year running mean filter applied. Only correlation coefficients statistically significant at the $95 \%$ confidence level are shown (significance level: 0.4). 
port across the ISR and are well above the significance level only in IPSLCM4.

The Nordic seas surface state anomalies associated with the anomalies in the Iceland-Scotland overflow strength are generally of barotropic character. The correlation pattern between the Iceland-Scotland overflow strength and the heat/salt content integrated over the whole water column (not shown) resembles the correlation pattern between the Iceland-Scotland overflow strength and the SST/SSS. The only exception is found for the heat content in the central Nordic seas in IPSLCM4, where a reduction rather than an increase in the heat content is associated with strong IcelandScotland overflow.

The Nordic seas temperature and salinity anomalies associated with the anomalies in the Iceland-Scotland overflow strength generally have a counteracting effect on the density. In MPI-ESM, the density anomalies in the eastern part of the Nordic seas are dominated by the temperature anomalies, resulting in anomalously light water associated with strong Iceland-Scotland overflow both at the surface (Fig. 6c) and integrated over the whole water column. Similar results are found for the eastern part of the Nordic seas in BCM (Fig. 8c) although correlation coefficients are much smaller than in MPI-ESM. In contrast, in IPSLCM4 the surface density anomalies in the central Nordic seas are dominated by the salinity anomalies, resulting in anomalously dense surface water associated with strong Iceland-Scotland overflow (Fig. 7c). Integrated over the whole water column, both anomalously low heat and high salt content in IPSLCM4 contribute to anomalously dense water in the central Nordic seas associated with strong Iceland-Scotland overflow.

As a consequence of the anomalously light water in the eastern part of the Nordic seas, anomalously high sea surface height (SSH, Figs. 6d and 8d) and anomalously deep isopycnals (Figs. 6e and 8e for the upper isopycnal defining the simulated Iceland-Scotland overflow) in MPI-ESM and BCM are associated with strong Iceland-Scotland overflow. In IPSLCM4, on the other hand, the anomalously dense water in the central Nordic seas associated with strong IcelandScotland overflow leads to anomalously low SSH (Fig. 7d) and anomalously shallow isopycnals (Fig. 7e).

Anomalous SSH and depth of the isopycnals in the Nordic seas may modify the pressure gradient across the ISR. In MPI-ESM, anomalously high SSH in the Nordic seas leads to an increase in the (barotropic) pressure north of the ISR. The importance of the barotropic pressure is in accordance with Olsen et al. (2008). Significant correlation coefficients between the Iceland-Scotland overflow strength and the SSH are also found south of the ridge. However, sensitivity experiments performed with a coarser-resolution version of MPI-ESM and no external forcing (Lohmann et al., 2014) suggest that the low-frequency variability of the IcelandScotland overflow strength can be suppressed when climatological hydrography (temperature and salinity) is prescribed in the Nordic seas and along the ISR but full hydrographic variability is used south of the ridge. This indicates that the SSH anomalies north (and at) the ridge are sufficient to determine the low-frequency variability of the IcelandScotland overflow strength. Furthermore, Olsen et al. (2008), analysing a simulation with the ocean component of MPIESM (with the same grid configuration as used in our study) forced with atmospheric reanalysis fields, link the variability of the Iceland-Scotland overflow strength mainly to anomalous SSH in the Nordic seas. Thus, we speculate that a strong Iceland-Scotland overflow in MPI-ESM is mainly caused by the anomalously high SSH north of the ISR.

Also in BCM, strong Iceland-Scotland overflow is mainly caused by anomalously high SSH in the eastern part of the Nordic seas in accordance with Sand $\varnothing$ et al. (2012). The authors analyse an ocean-only simulation with a regional version of the ocean component of BCM forced with atmospheric reanalysis fields and suggest that variations of the overflow transport across the ISR are mainly of a barotropic nature. In IPSLCM4, anomalously shallow isopycnals in the central Nordic seas lead to an increase in the (baroclinic) pressure north of the ISR, causing a strengthened IcelandScotland overflow. The importance of the baroclinic pressure has been suggested by, e.g., Jungclaus et al. (2008).

Regarding periods with strong external forcing, the composite pattern (not shown) with respect to the very weak Iceland-Scotland overflow following the major volcanic eruptions in years AD 1258 and 1815 (red lines in Fig. 3) in MPI-ESM and IPSLCM4 closely resembles the correlation pattern shown in Figs. 6 and 7. This result indicates that the above-discussed mechanism linking the IcelandScotland overflow strength with the Nordic seas surface state and density structure can also explain the very weak IcelandScotland overflow, which goes along with the cold events in the AMO index and particularly in the Nordic seas SST (Fig. 5).

Based on the results discussed in this section, we conclude that mechanism (ii), an influence of the Nordic seas surface state and density structure (positively correlated with the AMO index) on the Iceland-Scotland overflow strength, provides a possible explanation for the (simulated) similar variation of Iceland-Scotland overflow strength and AMO index.

\section{Discussion}

In this study we use simulations of the last millennium driven by external forcing reconstructions with three coupled climate models, to investigate two mechanisms as possible explanations for the similar variation of Iceland-Scotland overflow strength and AMO index. Similar variation of the two time series has been suggested from palaeo-reconstructions (Mjell et al., 2015) and is also largely found in the model simulations. Mechanism (i) is based on a large-scale link through the strength of the MOC, while mechanism (ii) is based on 
a more local link through the influence of the Nordic seas surface state and density structure on the Iceland-Scotland overflow strength. Mechanism (ii) also involves the largescale ocean circulation through the northward transport of heat and salt across the ISR, which affects the Nordic seas surface state.

The (simulated) basin-wide AMO index is dominated by the low-latitude SST variability that is strongly influenced by the external forcing, in particular long-lasting effects of major volcanic eruptions (e.g. Otterå et al., 2010; Mignot et al., 2011; Zanchettin et al., 2012). Similar to the conclusions from these previous studies, our analysis indicates that the (simulated) basin-wide AMO index is not predominantly an expression of MOC variations. This result is different from studies based on control simulations where multidecadal North Atlantic SST anomalies, as reflected in the AMO index, are associated with multidecadal MOC variations (e.g. Delworth and Mann, 2000; Latif et al., 2004; Knight et al., 2005; Zanchettin et al., 2014). We conclude that mechanism (i) is not sufficient to explain the (simulated) similar variation of Iceland-Scotland overflow strength and AMO index.

Rather, Iceland-Scotland overflow strength and AMO index are (in the simulations) linked through mechanism (ii). The Nordic seas surface state and density structure, which are positively correlated with the AMO index, affect via changes in SSH and depths of the isopycnals the pressure gradient across the ISR in the core depth of the overflow and consequently the strength of the Iceland-Scotland overflow (e.g. Hansen and Østerhus, 2007; Jungclaus et al., 2008; Olsen et al., 2008; Sandø et al., 2012). Since the AMO index has no direct influence on the Iceland-Scotland overflow strength, mechanism (ii) crucially depends on the covarying of AMO index and Nordic seas surface state, as for the simulations shown in Fig. 4 (left panels).

The details of the discussed mechanisms vary between the different models, and the models also exhibit biases such as the unrealistic flow path of the Iceland-Scotland overflow water south of the ISR. The model differences and biases underline, on one hand, the importance of multi-model studies but, on the other hand, also impose some uncertainty on the mechanism underlying the similar variation of IcelandScotland overflow strength and AMO index in the real world.

One difference in the discussed mechanisms is the importance of the barotropic pressure (MPI-ESM, anomalously light water in the Nordic seas associated with strong IcelandScotland overflow) or the baroclinic pressure (IPSLCM4, anomalously dense water in the Nordic seas associated with strong Iceland-Scotland overflow). The reason for this difference is not clear. Possible explanations are differences in the background state or in the amplitude of the low-frequency variability in the Nordic seas. IPSLCM4 exhibits a colder and fresher mean surface state in the eastern part of the Nordic seas compared to MPI-ESM (not shown). Differences amount to $2-3^{\circ} \mathrm{C}$ for SST and about 0.5 psu for SSS. This re- sult is in agreement with IPSLCM4 exhibiting a cold mean state in the North Atlantic in general (Marti et al., 2010, based on control simulations). The two model simulations also differ with respect to the amplitude of the low-frequency surface state variability in the eastern part of the Nordic seas, determined from the standard deviation (not shown). For SST, the low-frequency variability is larger in MPI-ESM, while for SSS, larger variability is found in IPSLCM4.

Although the pressure gradient control of the IcelandScotland overflow strength is similar in BCM as in the two other models, the correlation between the Iceland-Scotland overflow strength and the AMO index is weaker in BCM. One possible explanation is that in BCM the anomalously high SSH in the eastern part of the Nordic seas associated with strong Iceland-Scotland overflow is to a large extent caused by increased northward wind stress (Fig. 8f) via increased Ekman transport towards the Norwegian coast. Such wind stress anomalies are not seen in the two other models (Figs. 6f and 7f). The wind stress anomalies over the Nordic seas are not necessarily in phase with the low- and mid-latitude SST variability (as reflected in the AMO index), but affect the strength of the Iceland-Scotland overflow.

In addition, in BCM the strength of the MOC influences the Nordic seas surface state to a much larger extent than in the two other models (right panels in Fig. 4), which is in agreement with Otterå et al. (2010). The authors also show a significant out-of-phase relation between the strength of the MOC and the AMO index in the externally forced BCM simulation. Consequently, in BCM a much weaker correlation is found between the AMO index and the Nordic seas surface state, which affects the strength of the Iceland-Scotland overflow.

In MPI-ESM and IPSLCM4, on the other hand, there is evidence of an influence of the external forcing (major volcanic eruptions) on the Nordic seas surface state (Mignot et al., 2011; Zanchettin et al., 2012). In both models, the MOC signature on the North Atlantic surface state in the externally forced simulations is much weaker compared to the respective control simulation (not shown). The relatively strong influence of the external forcing on the North Atlantic SST including the Nordic seas helps to phase the AMO index (dominated by the low-latitude SST variability) and the IcelandScotland overflow strength (influenced by the Nordic seas surface state and density structure) in these two models, especially during periods of strong external forcing.

\section{Conclusions}

To summarise, the following main conclusions can be drawn from our study:

- Similar low-frequency variations of Iceland-Scotland overflow strength and AMO index, as suggested from palaeo-reconstructions (Mjell et al., 2015), can largely 
be seen in coupled climate model simulations of the last millennium, driven by external forcing reconstructions.

- The basin-wide AMO index in the externally forced simulations is dominated by the low-latitude SST variability, which according to the literature is strongly influenced by the external forcing and is not predominantly driven by variations in the strength of the MOC.

- The simulated similar variation of Iceland-Scotland overflow strength and AMO index is based on the influence of the Nordic seas surface state and density structure, which are positively correlated with the AMO index, on the pressure gradient across the ISR. According to literature, the latter affects the Iceland-Scotland overflow strength.

- However, the importance of the barotropic or baroclinic pressure gradient differs among models. In the model showing a weaker correlation between the IcelandScotland overflow strength and the AMO index, the wind stress in the Nordic seas also influences the overflow strength.

- Our study demonstrates that palaeo-climate simulations provide a useful tool to understand mechanisms and large-scale connections associated with localised and rather sparse palaeo-observations. With respect to palaeo-climate simulations, the simulations of the last millennium performed within the framework of the CMIP5 and PMIP3 projects provide an excellent database for future studies.

Acknowledgements. This work was supported by the European Community's 7th framework programme (FP7/2007-2013) under grant agreement no. GA212643 (THOR: Thermohaline circulation - at risk?, 2008-2012). K. Lohmann also received funding through the Cluster of Excellence "CLISAP" funded by the German Science Foundation (DFG). D. Matei was supported by the Federal Ministry for Education and Research (BMBF) NORTH ATLANTIC and RACE projects. The authors wish to thank Davide Zanchettin for a critical review of the manuscript prior to submission. Fruitful discussions with other colleagues at the Max Planck Institute for Meteorology are also acknowledged. The authors greatly acknowledge helpful comments by Flavio Lehner and one anonymous reviewer, which improved the manuscript a lot. The MPI-ESM simulation was conducted at the German Climate Computing Center (DKRZ). This study is a contribution to the Centre for Climate Dynamics at the Bjerknes Centre.

The service charges for this open access publication have been covered by the Max Planck Society.

Edited by: H. Goosse

\section{References}

Ammann, C., Meehl, G., Washington, W., and Zender, C.: A monthly and latitudinally varying volcanic forcing dataset in simulations of 20th century climate, Geophys. Res. Lett., 30, 1657, doi:10.1029/2003GL016875, 2003.

Ba, J., Keenlyside, N., Latif, M., Park, W., Ding, H., Lohmann, K., Mignot, J., Menary, M., Otterå, O. H., Wouters, B., Salas-Melia, D., Oka, A., Belluci, A., and Volodin, E.: Multi-model comparison for North Atlantic multi-decadal variability, Clim. Dynam., 43, 2333-2348, 2014.

Bleck, R. and Smith, L.: A wind-driven isopycnic coordinate model of the north and equatorial Atlantic Ocean, 1. Model development and supporting experiments, J. Geophys. Res., 95, 32733285, 1990.

Bleck, R., Rooth, C., Hu, D., and Smith, L.: Salinity-driven thermocline transients in a wind- and thermohaline-forced isopycnic coordinate model of the North Atlantic, J. Phys. Oceanogr., 22, 1486-1505, 1992.

Boessenkool, K., Hall, I. R., Elderfield, H., and Yashayaev, I.: North Atlantic climate and deep-ocean flow speed changes during the last 230 years, Geophys. Res. Lett., 34, L13614, doi:10.1029/2007GL030285, 2007.

Crowley, T. J., Baum, S. K., Kim, K. Y., Hegerl, G. C., and Hyde, W. T.: Modeling ocean heat content changes during the last millennium, Geophys. Res. Lett., 30, 1932, doi:10.1029/2003GL017801, 2003.

Crowley, T. J., Zielinski, G., Vinther, B., Udisti, R., Kreutz, K., Cole-Dai, J., and Castellano, J.: Volcanism and the Little Ice Age, PAGES Newsletter, 16, 22-23, 2008.

Delworth, T. and Mann, M. E.: Observed and simulated multidecadal variability in the Northern Hemisphere, Clim. Dynam., 16, 661-676, 2000.

Déqué, M., Dreveton, C., Braun, A., and Cariolle, D.: The ARPEGE/IFS atmosphere model: A contribution to the French community climate modelling, Clim. Dynam., 10, 249-266, 1994.

Fichefet, T., and Maqueda, M. A. M.: Sensitivity of a global sea ice model to the treatment of ice thermodynamics and dynamics, J. Geophys. Res., 102, 12609-12646, 1997.

Furevik, T., Bentsen, M., Drange, H., Kindem, I., Kvamstø N. G., and Sorteberg, A.: Description and evaluation of the Bergen climate model: ARPEGE coupled with MICOM, Clim. Dynam., 21, 27-51, 2003.

Gao, C., Robock, A., and Ammann, C.: Volcanic forcing of climate over the last 1500 years: An improved ice-core based index for climate models, J. Geophys. Res., 113, D2311, doi:10.1029/2008JD010239, 2008.

Gastineau, G. and Frankignoul, C.: Cold-season atmospheric response to the natural variability of the Atlantic meridional overturning circulation, Clim. Dynam., 39, 37-57, 2012.

Goosse, H. and Renssen, H.: Regional response of the climate system to solar forcing: the role of the ocean, Space Sci. Rev., 125, 227-235, 2006.

Gray, S., Graumlich, L., Betancourt, J., and Pederson, G.: A tree-ring based reconstruction of the Atlantic multidecadal oscillation since $1567 \mathrm{AD}$, Geophys. Res. Lett., 31, L12205, doi:10.1029/2004GL019932, 2004.

Hansen, B. and Østerhus, S.: Faroe Bank Channel overflow 1995 2005, Prog. Oceanogr., 75, 817-856, 2007. 
Hansen, B., Turrell, W., and Østerhus, S.: Decreasing overflow from the Nordic seas into the Atlantic Ocean through the Faroe Bank channel since 1950, Nature, 411, 927-930, 2001.

Hansen, B., Østerhus, S., Turrell, B., Jónsson, S., Valdimarsson, H., Hátún H., and Olsen, S. M.: The inflow of Atlantic water, heat, and salt to the Nordic Seas across the Greenland-Scotland Ridge, in: Arctic-Subarctic Ocean Fluxes: Defining the role of the Northern Seas in Climate, edited by: Dickson, D., Meincke, J., and Rhines, P., Springer Verlag, 15-43, 2008.

Hourdin, F., Musat, I., Bony, S., Braconnot, P., Codron, F., Dufresne, J., Fairhead, L., Filiberti, M. A., Friedlingstein, P., Grandpeix, J. Y., Krinner, G., Levan, P., Li, Z., and Lott, F.: The LMDZ4 general circulation model: climate performance and sensitivity to parametrized physics with emphasis on tropical convection, Clim. Dynam., 27, 787-813, 2006.

Jungclaus, J. H., Haak, H., Latif, M., and Mikolajewicz, U.: ArcticNorth Atlantic interactions and multidecadal variability of the meridional overturning circulation, J. Clim., 18, 4013-4031, 2005.

Jungclaus, J. H., Macrander, A., and Käse, R.: Modelling the overflows across the Greenland-Scotland Ridge, in: Arctic-Subarctic Ocean Fluxes: Defining the role of the Northern Seas in Climate, edited by: Dickson, D., Meincke, J., and Rhines, P., Springer Verlag, 527-549, 2008.

Jungclaus, J. H., Fischer, N., Haak, H., Lohmann, K., Marotzke, J., Matei, D., Mikolajewicz, U., Notz, D., and von Storch, J. S.: Characteristics of the ocean simulations in Max Planck Institute Ocean Model (MPIOM), the ocean component of the MPI-Earth System Model, J. Adv. Model. Earth Syst., 5, 422-446, 2013.

Jungclaus, J. H., Lohmann, K., and Zanchettin, D.: Enhanced 20thcentury heat transfer to the Arctic simulated in the context of climate variations over the last millennium, Clim. Past, 10, 22012213, doi:10.5194/cp-10-2201-2014, 2015.

Kavvada, A., Ruiz-Barradas, A., and Nigam, S.: AMO's structure and climate footprint in observations and IPCC AR5 climate simulations, Clim. Dynam., 41, 1345-1364, 2013.

Knight, J., Allan, R., Folland, C., Vellinga, M., and Mann, M. E.: A signature of persistent natural thermohaline circulation cycles in observed climate, Geophys. Res. Lett., 32, L20708, doi:10.1029/2005GL024233, 2005.

Köhl, A. and Stammer, D.: Variability of the meridional overturning in the North Atlantic from the 50-year GECCO state estimate, J. Phys. Oceanogr., 38, 1913-1930, 2008.

Langehaug, H. R., Medhaug, I., Eldevik, T., and Otterå, O. H.: Arctic/Atlantic exchanges via the subpolar gyre, J. Clim., 25, 24212439, 2012a.

Langehaug, H. R., Rhines, P. B., Eldevik, T., Mignot, J., and Lohmann, K.: Water mass transformation and the North Atlantic Current in three multicentury climate model simulations, J. Geophys. Res., 117, C11001, doi:10.1029/2012JC008021, 2012b.

Latif, M., Roeckner, E., Botzet, M., Esch, M., Haak, H., Hagemann, S., Jungclaus, J. H., Legutke, S., Marsland, S., Mikolajewicz, U., and Mitchell, J.: Reconstructing, monitoring and predicting decadal-scale changes in the North Atlantic thermohaline circulation with sea surface temperature, J. Clim., 17, 1605-1614, 2004.

Lehner, F., Born, A., Raible, C. C., and Stocker, T. S.: Amplified inception of European Little Ice Age by sea ice - ocean - atmosphere feedbacks, J. Clim., 26, 7586-7602, 2013.
Lohmann, K., Jungclaus, J. H., Matei, D., Mignot, J., Menary, M., Langehaug, H. R., Ba, J., Gao, Y. Q., Otterå, O. H., Park, W., and Lorenz, S.: The role of subpolar deep water formation and Nordic Seas overflows in simulated multidecadal variability of the Atlantic meridional overturning circulation, Ocean Sci., 10, 227-241, 2014, http://www.ocean-sci.net/10/227/2014/.

Madec, G., Delecluse, P., Imbard, M., and Levy, M.: OPA 8.1, ocean general circulation model reference manual, Notes du pole de modélisation, 11, Institut Pierre-Simon Laplace (IPSL), Paris, France, 91 pp., 1998.

Mann, M. E., Zhang, Z., Rutherford, S., Bradley, R. S., Hughes, M. K., Shindell, D., Ammann, C., Faluvegi, G., and Ni, F.: Global signatures and dynamical origins of the Little Ice Age and Medieval Climate Anomaly, Science, 326, 1256-1260, 2009.

Marsland, S., Haak, H., Jungclaus, J. H., Latif, M., and Röske, F.: The Max Planck Institute global ocean/sea ice model with orthogonal curvilinear coordinates, Ocean Modell., 5, 91-127, 2003.

Marti, O., Braconnot, P., Dufresne, J. L., Bellier, J., Benshila, R., Bony, S., Brockmann, P., Cadule, P., Caubel, A., Codron, F., de Noblet, N., Denvil, S., Fairhead, L., Fichefet, T., Foujols, M. A., Friedlingstein, P., Goosse, H., Grandpeix, J. Y., Guilyardi, E., Hourdin, F., Idelkadi, A., Kageyama, M., Krinner, G., Lévy, C., Madec, G., Mignot, J., Musat, I., Swingedouw, D., and Talandier, C.: Key features of the IPSL ocean atmosphere model and its sensitivity to atmospheric resolution, Clim. Dynam., 34, 1-26, 2010.

Menary, M., Park, W., Lohmann, K., Vellinga, M., Palmer, M., Latif, M., and Jungclaus, J. H.: A multimodel comparison of centennial Atlantic meridional overturning circulation variability, Clim. Dynam., 38, 2377-2388, 2012.

Mignot, J., Khodri, M., Frankignoul, C., and Servonnat, J.: Volcanic impact on the Atlantic Ocean over the last millennium, Clim. Past, 7, 1439-1455, 2011, http://www.clim-past.net/7/1439/2011/.

Mjell, T. L., Ninnemann, U. S., Kleiven, H. F., and Hall, I. R.: Multidecadal changes in Iceland Scotland Overflow Water vigor over the last 600 years and its relationship to climate, Geophys. Res. Lett., submitted, 2015.

Moreno-Chamarro, E., Zanchettin, D., Lohmann, K., and Jungclaus, J. H.: Internally generated decadal cold events in the northern North Atlantic and their possible implications for the demise of the Norse settlements in Greenland, Geophys. Res. Lett., doi:10.1002/2014GL062741, online first, 2015.

Msadek, R. and Frankignoul, C.: Atlantic multidecadal oceanic variability and its influence on the atmosphere in a climate model, Clim. Dynam., 33, 45-62, 2009.

Myneni, R. B., Nemani, R. R., and Running, S. W.: Estimation of global leaf area index and absorbed par using radiative transfer models, Ieee T. Geosci. Remote., 35, 1380-1393, 1997.

Notz, D., Haumann, A., Haak, H., Jungclaus, J. H., and Marotzke, J.: Sea-ice evolution in the Arctic as modeled by Max Planck Institute for Meteorology's Earth System Model, J. Adv. Model. Earth Syst., 5, 173-194, 2013.

Olsen, S. M., Hansen, B., Quadfasel, D., and Østerhus, S.: Observed and modeled stability of overflow across the Greenland-Scotland ridge, Nature, 455, 519-523, 2008. 
Ortega, P., Montoya, M., González-Rouco, F., Mignot, J., and Legutke, S.: Variability of the Atlantic meridional overturning circulation in the last millennium and two IPCC scenarios, Clim. Dynam., 38, 1925-1947, 2012.

Otterå, O. H., Bentsen, M., Bethke, I., and Kvamstø, N. G.: Simulated pre-industrial climate in Bergen Climate Model (version 2): model description and large-scale circulation features, Geosci. Model Dev., 2, 197-212, 2009.

Otterå, O. H., Bentsen, M., Drange, H., and Suo, L.: External forcing as a metronome for Atlantic multidecadal variability, Nat. Geosci., 3, 688-694, 2010.

Park, W. and Latif, M.: Atlantic meridional overturning circulation response to idealized external forcing, Clim. Dynam., 39, 17091726, 2012.

Pongratz, J., Reick, C. H., Raddatz, T., and Claussen, M.: A reconstruction of global agricultural areas and land cover for the last millennium, Global Biogeochem. Cy., 22, GB3018, doi:10.1029/2007GB003153, 2008.

Salas-Melia, D.: A global coupled sea ice-ocean model, Ocean Modell., 4, 137-172, 2002.

Sand $\varnothing$, A. B., Nilsen, J. E. Ø., Eldevik, T., and Bentsen, M.: Mechanisms for variable North Atlantic - Nordic Seas exchanges, J. Geophys. Res., 117, C12006, doi:10.1029/2012JC008177, 2012.

Schlesinger, M. E. and Ramankutty, N.: An oscillation in the global climate system of period 65-70 years, Nature, 367, 723-726, 1994.

Schmidt, G., Jungclaus, J. H., Ammann, C., Bard, E., Braconnot, P., Crowley, T. J., Delaygue, G., Joos, F., Krivova, N. A., Muscheler, R., Otto-Bliesner, B. L., Pongratz, J., Shindell, D. T., Solanki, S. K., Steinhilber F., and Vieira, L. E. A.: Climate forcing reconstructions for use in PMIP simulations of the last millennium (v1.0), Geosci. Model Dev., 4, 33-45, 2011.

Servonnat, J., Yiou, P., Khodri, M., Swingedouw, D., and Denvil, S.: Influence of solar variability, $\mathrm{CO}_{2}$ and orbital forcing between 1000 and 1850 AD in the IPSLCM4 model, Clim. Past, 6, 445460, 2010,

http://www.clim-past.net/6/445/2010/.

Stenchikov, G., Delworth, T. L., Ramswamy, V., Stouffer, R. J., Wittenberg, A., and Zeng, F.: Volcanic signals in oceans, J. Geophys. Res., 114, D16104, doi:10.1029/2008JD011673, 2009.

Stevens, B., Giorgetta, M., Esch, M., Mauritsen, T., Crueger, T., Rast, S., Salzmann, M., Schmidt, H., Bader, J., Block, K., Brokopf, R., Fast, I., Kinne, S., Kornblueh, L., Lohmann, U., Pincus, R., Reichler, T., and Roeckner, E.: Atmospheric component of the MPI-M Earth System Model: ECHAM6, J. Adv. Model. Earth Syst., 5, 146-172, 2013.

Svendsen, L., Hetzinger, S., Keenlyside, N., and Gao, Y. Q.: Marine-based multiproxy reconstruction of Atlantic multidecadal variability, Geophys. Res. Lett., 41, 2013GL059076, doi:10.1002/2013GL059076, 2014.
Swingedouw, D., Terray, L., Cassou, C., Voldoire, A., Salas-Melia, D., and Servonnat, J.: Natural forcing of climate during the last millennium: Fingerprint of solar variability and NAO, Clim. Dynam., 36, 1349-1364, 2011.

Swingedouw, D., Mignot, J., Labetoule, S., Guilyardi, E., and Madec, G.: Initialisation and predictability of the AMOC over the last 50 years in a climate model, Clim. Dynam., 40, 23812399, 2013.

Terray, L.: Evidence for multiple drivers of North Atlantic multidecadal climate variability, Geophys. Res. Lett., 39, L19712, doi:10.1029/2012GL053046, 2012.

Terray, L. and Thual, O.: Oasis: le couplage océan-atmosphére, La Météorologie, 10, 50-61, 1995.

Trenberth, K. and Shea, D.: Atlantic hurricanes and natural variability in 2005, Geophys. Res. Lett., 33, L12704, doi:10.1029/2006GL026894, 2006.

Valcke, S., Terray, L., and Piacentini, A.: Oasis 2.4, Ocean atmosphere sea ice soil: user's guide, Tech. Rep. TR/CMGC/00/10, CERFACS, Toulouse, France, 2000.

Valcke, S., Claubel, A., Declat, D., and Terray, L.: OASIS Ocean Atmosphere Sea Ice Soil user's guide, Tech. Rep. TR/CMGC/03/69, CERFACS, Toulouse, France, 2003.

Vieira, L. and Solanki, S. K.: Evolution of the solar magnetic flux on time scales of years to millennia, Annu. Rev. Astron. Astr., 509, arXiv/0911.4396, doi:10.1051/00046361/200913276, 2009.

Vieira, L., Solanki, S. K., Krivova, N. A., and Usoskin, I.: Evolution of the solar irradiance during the Holocene, Astron. Astroph., 531, A6, doi:10.1051/0004-6361/201015843, 2011.

Wold, C.: Cenozoic sediment accumulation on drifts in the northern North Atlantic, Paleoceanography, 9, 917-941, 1994.

Zanchettin, D., Timmreck, C., Graf, H. F., Rubino, A., Lorenz, S., Lohmann, K., Krüger, K., and Jungclaus, J. H.: Bi-decadal variability excited in the coupled ocean-atmosphere system by strong tropical volcanic eruptions, Clim. Dynam., 39, 419-444, 2012.

Zanchettin, D., Rubino, A., Matei, D., Bothe, O., and Jungclaus, J. H.: Multidecadal-to-centennial SST variability in the MPI-ESM simulation ensemble for the last millennium, Clim. Dynam., 40, 1301-1318, 2013.

Zanchettin, D., Bothe, O., Müller, W. A., Bader, J., and Jungclaus, J. H.: Different flavors of the Atlantic Multidecadal Variability, Clim. Dynam., 42, 381-399, 2014.

Zhang, L. and Wang, C.: Multidecadal North Atlantic sea surface temperature and Atlantic meridional overturning circulation variability in CMIP5 historical simulations, J. Geophys. Res., 118, 5772-5791, 2013.

Zhong, Y., Miller, G. H., Otto-Bliesner, B. L., Holland, M. M., Bailey, D. A., Schneider, D. P., and Geirsdottir, A.: Centennialscale climate change from decadally-paced explosive volcanism: a couled sea ice-ocean mechanism, Clim. Dynam., 37, 2373-2387, 2011. 